\title{
A Methodological Review of Development and Assessment of Behavioral Models of Depression in Rats
}

\author{
Fahime Zavvari $^{1,2}$, Fariba Karimzadeh ${ }^{3 *}$ \\ ${ }^{1}$ Shefa Neuroscience Research Center, Khatam Alanbia Hospital, Tehran, Iran \\ ${ }^{2}$ Department of Physiology, Iran University of Medical Sciences, Tehran, Iran \\ ${ }^{3}$ Cellular and Molecular Research Center, Iran University of Medical Sciences, Tehran, Iran
}

\section{ABSTRACT}

Introduction: Depression is a chronic, multifactorial, and potentially life-threatening mental disorder that affects up to $20 \%$ of the worldwide population. Over several decades, numerous animal models have been established to study the underlying pathophysiology of depression and to test novel antidepressant treatment strategies. The criteria for identifying animal models of depression based on two principles: the side effects of antidepressants and responses to stress. Here, we summarized depression animal models, including learned helplessness, chronic mild stress, social defeat paradigms, and early life stress. Also, we reviewed the behavioral tests for screening antidepressants, such as forced swimming test, tail suspension test, sucrose preference test, open field test, elevated plus maze test, novelty-induced hypophagia, intracranial self-stimulation, and dark/light box test. Conclusion: The complexity of the depression and its etiologic as well as pathophysiological similarities with anxiety disorders challenge the developing of a comprehensive animal model that accurately reflect different aspects of depression. However, these animal models could so far help in a better understanding of the pathophysiology of depression.

\section{Key words:}

1. Depression

2. Animals

3. Rats

* Corresponding Author: Fariba Karimzadeh

E-mail: Fariba_karimzade@yahoo.com 


\title{
مرورى بر روشهاى ايجاد و ارزيابى مدلهاى رفتارى افسردتى در موشهاى صحرايى
}

\author{
فهيمه زوّارى ז'، فريبا كريم زاده”" \\ 'مركز تحقيقات علوم اعصاب شفا، بيمارستان خاتم الانبياء، تهران، ايران

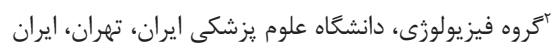

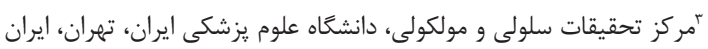

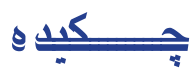

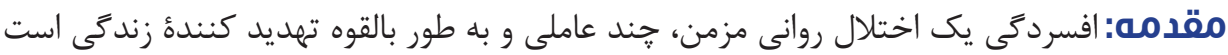

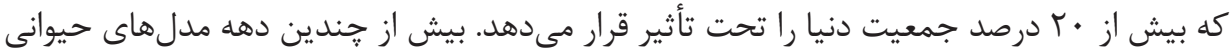

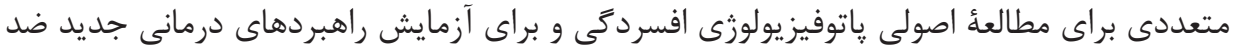

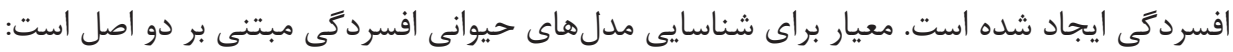

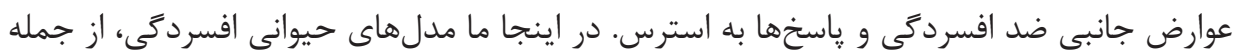

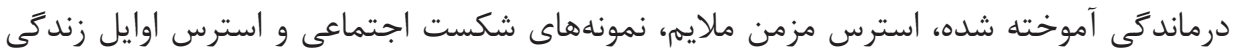

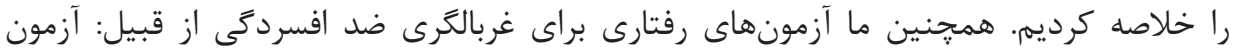

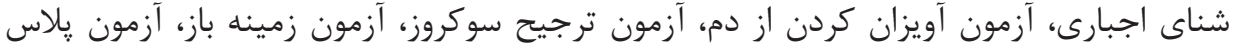

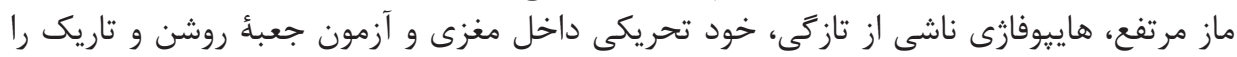

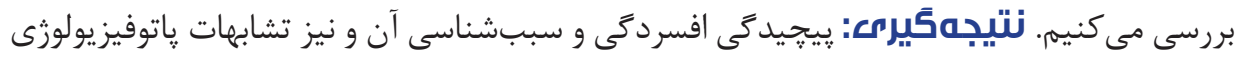

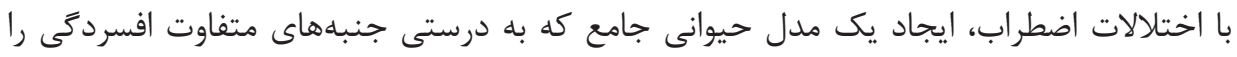

كليد وازهها:

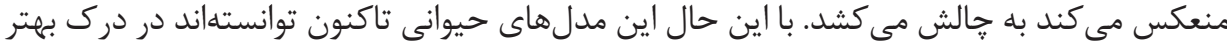
ياتوفيزيولوزى افسردگى كمك كنئد

\footnotetext{
r. موش حسوان صحرايى
}

$$
\text { " نويسنده مسئول: فريبا كريم زاده }
$$

آدرس الكترونيكى: Fariba_karimzade@yahoo.com 


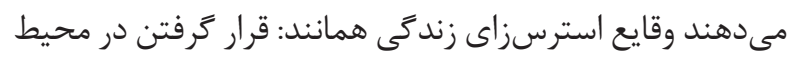

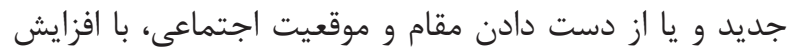

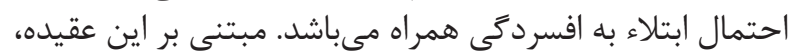

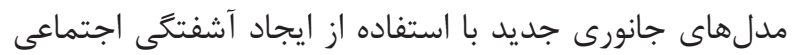

بهنوان عامل استرسزا ايجاد شد (ه).

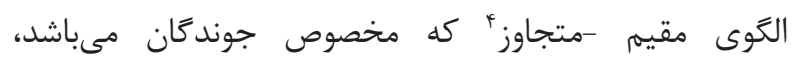

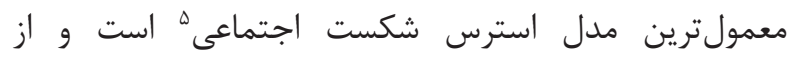

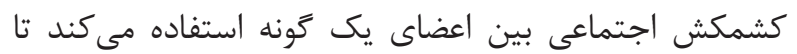

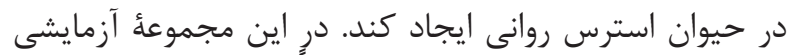

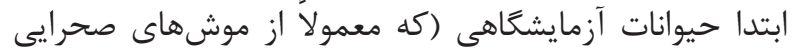

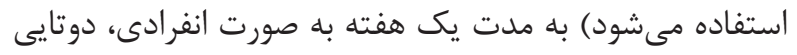

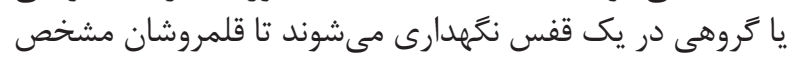

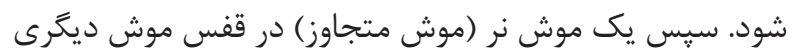

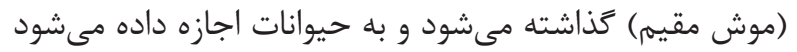

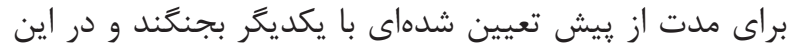

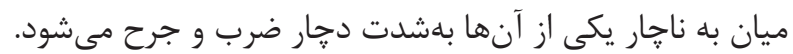

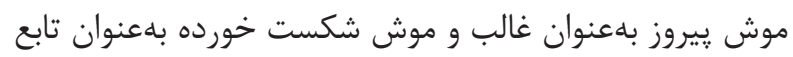
در نظر كرفته مىشود.

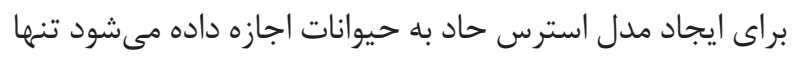

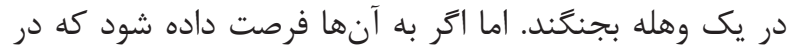

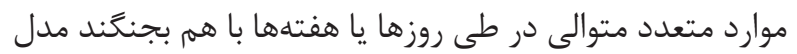

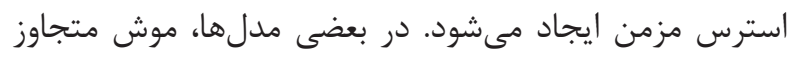

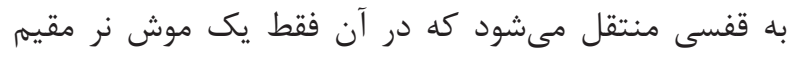

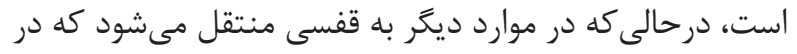

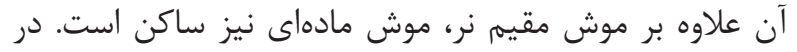

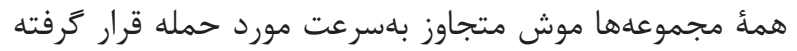

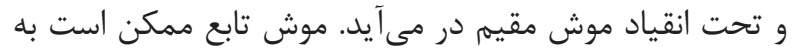

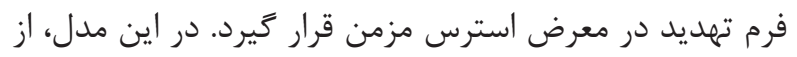

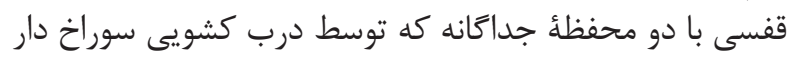

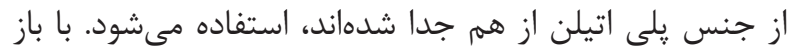

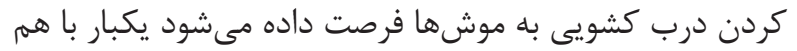

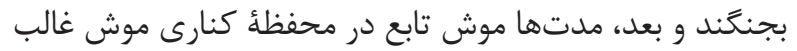

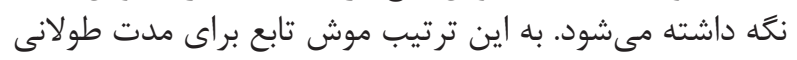

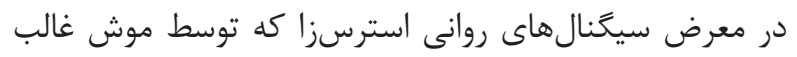

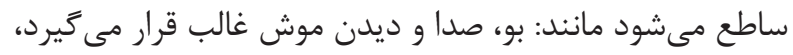
بدون اينكه صدمهٔ فيزيكى ديكرى را تجربه كند (Y) ، (G).

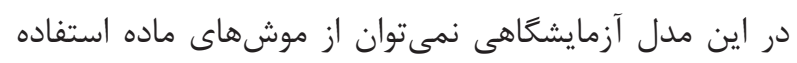

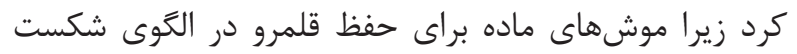

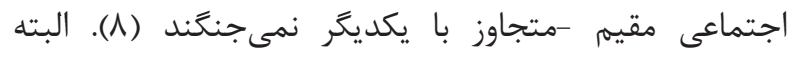

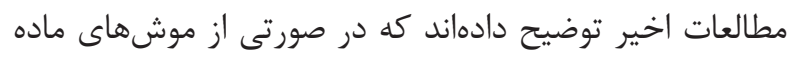

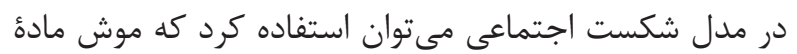

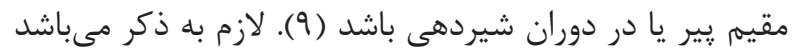

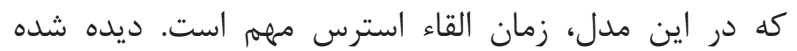

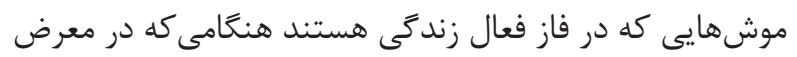

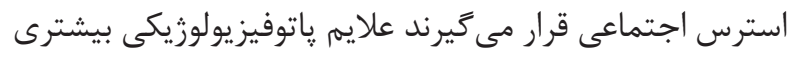

${ }^{1}$ Neurotransmitters

${ }^{2}$ Strategies

${ }^{3}$ Olfactory bulbectomy

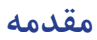

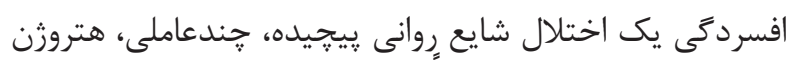

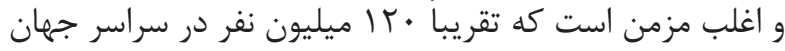

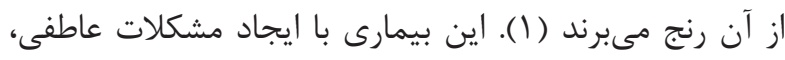

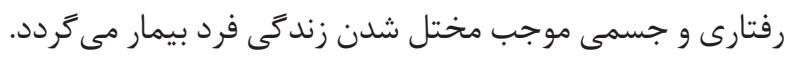

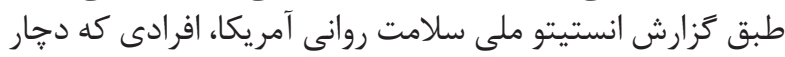

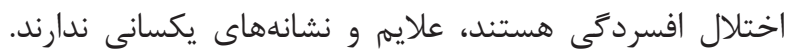

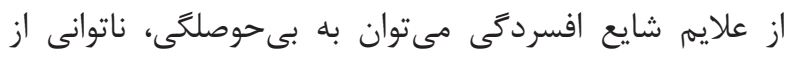

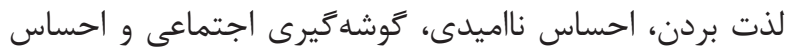

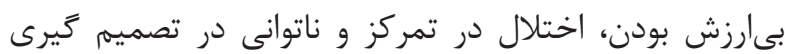

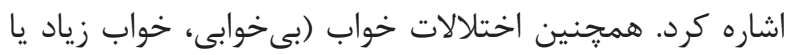

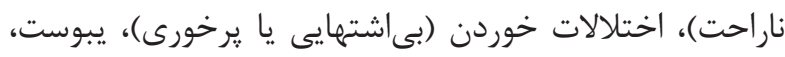

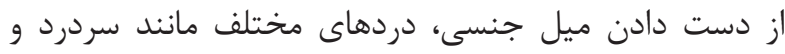

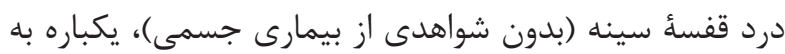

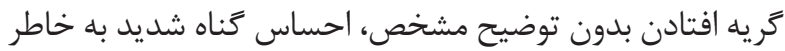

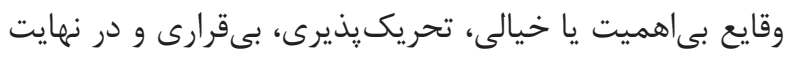

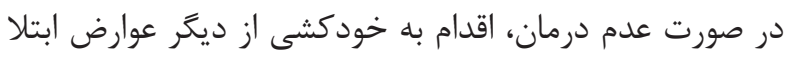

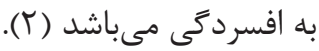

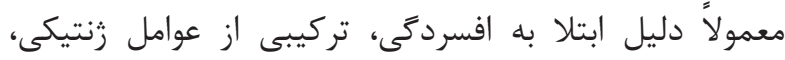

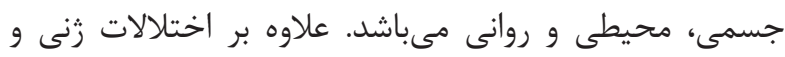

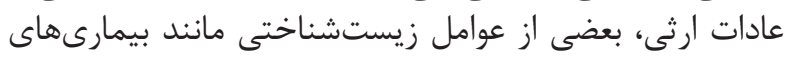

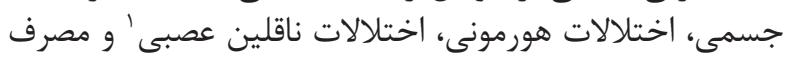

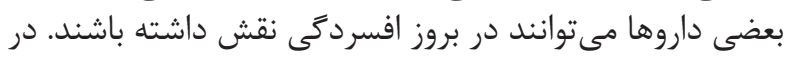

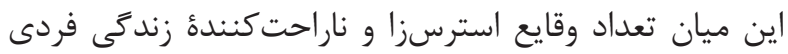

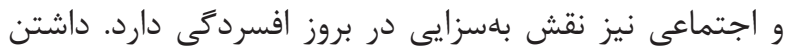

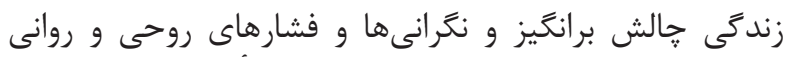

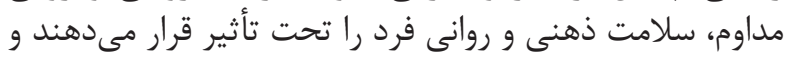

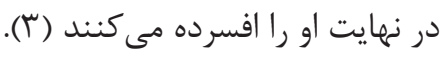

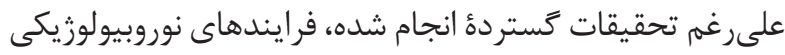

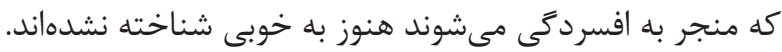

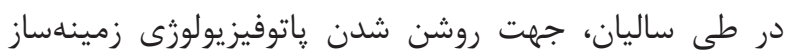

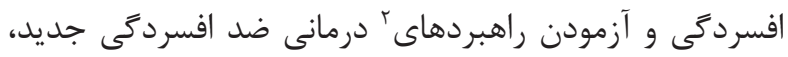

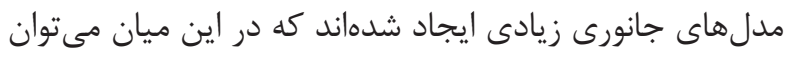

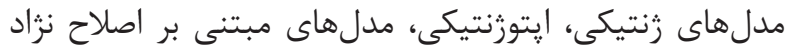

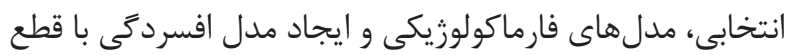

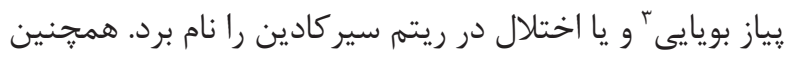

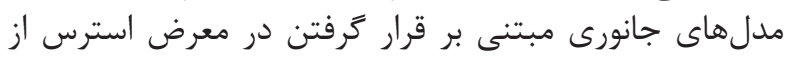

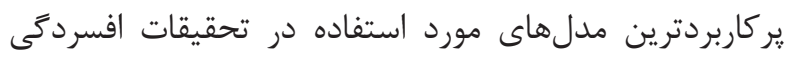

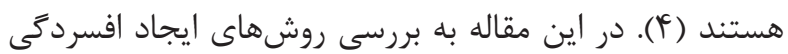

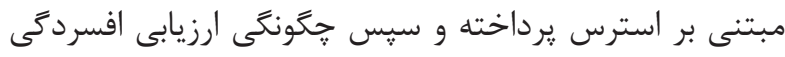
در مدلهاى حيوانى را مرور مى كنيمه واخته

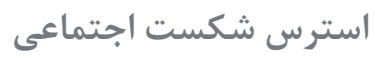

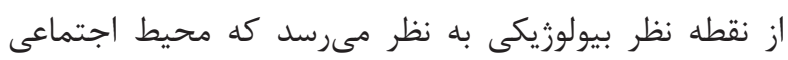
يك منبع قابل ملاحظة استرس است. يافتههاى محققان نشان

${ }^{4}$ Resident-intruder

${ }^{5}$ Social defeat stress 
(ب (1). درماندگى آموخته يكى از اولين مدل هايى است كه توسط

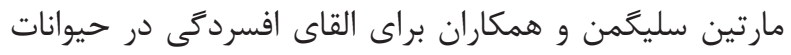

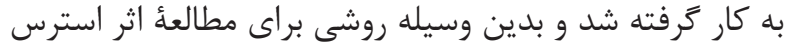
غيرقابل كنترل مهيا كردند (1) (1). طرح آزمايشى كلاسيك اين مدل شامل سه گرتروه مىباشد كه

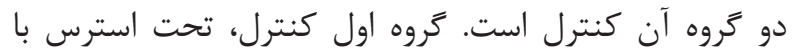

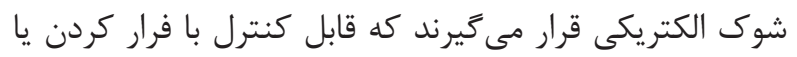

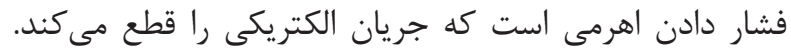

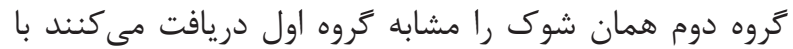

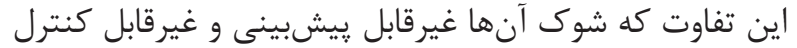

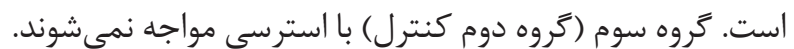

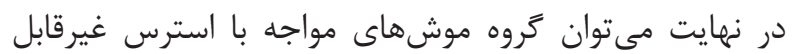

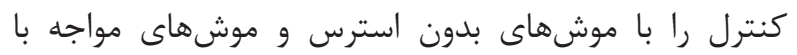

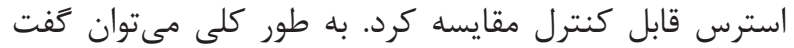

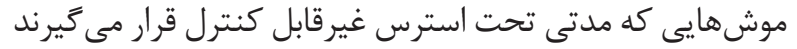

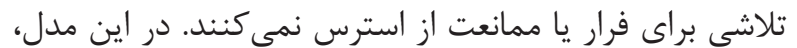

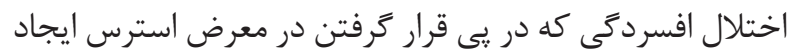

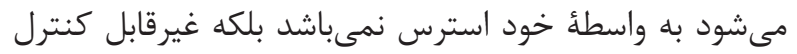
بودن استرس وارد شده عامل تعيين كننده مىباشد ندي (ها (1).

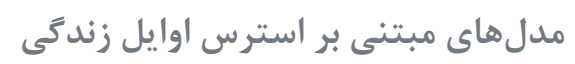

اين مدل بر مبناى مشاهداتى است كه نشان مى دهند تجران تجربيات

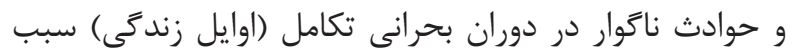

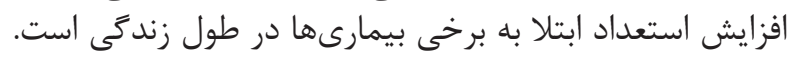

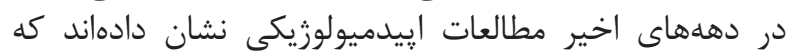

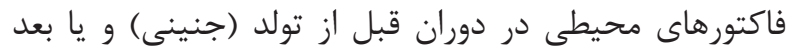

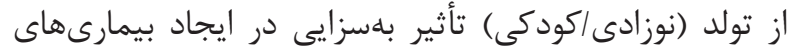

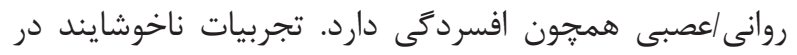

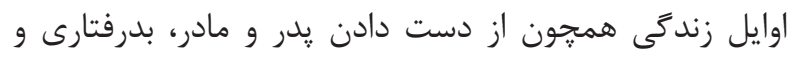

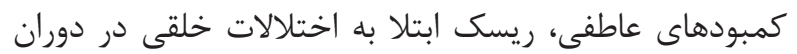
بعدى زندگى را افزايش مى دهند.

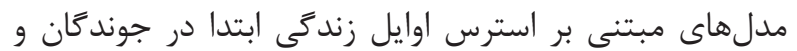

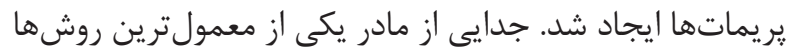

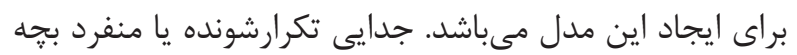

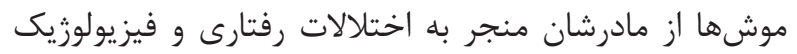

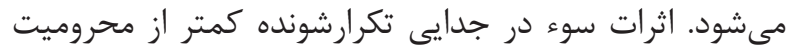

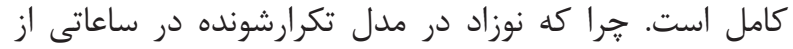

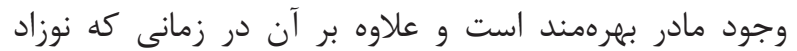

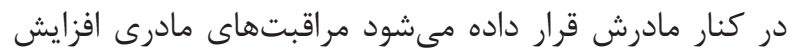

مى (19) - (19).

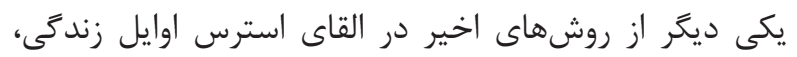

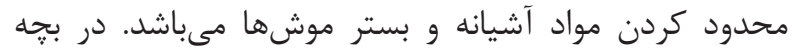

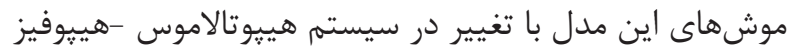

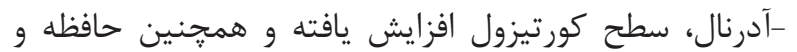

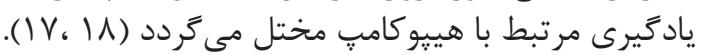

${ }^{6}$ Chronic mild stress

${ }^{7}$ Anhedonia

${ }^{8}$ Stressors
نسبت به موشهايى نشان مى دهند كه در زمان غيرفعال زند إكى

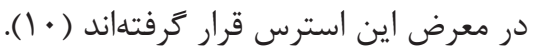

استرس خفيف مزمن

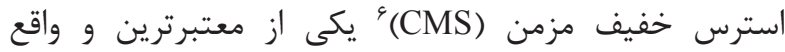

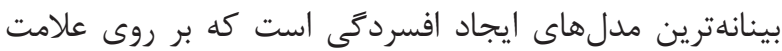

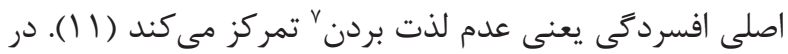

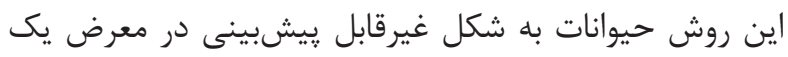
سرى از عوامل استرسزاى ^ملايم قرار مى گيرني

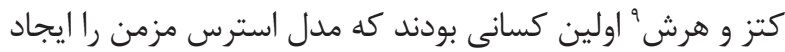

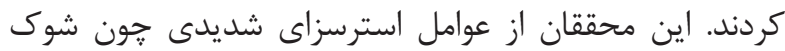

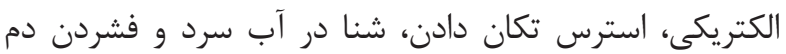

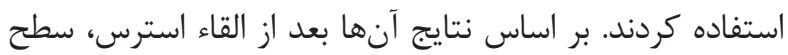

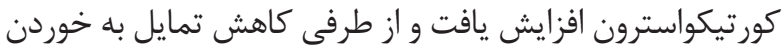

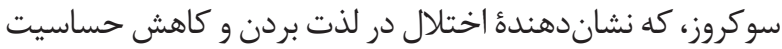

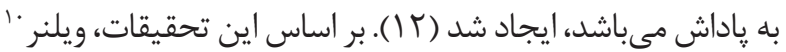

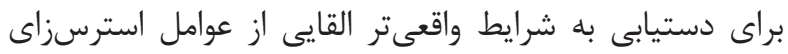

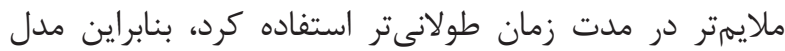

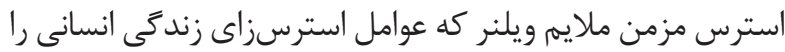
بهتر از مدل كتز تقليد مى كرد جايكزين مدين مدل كتز شد.

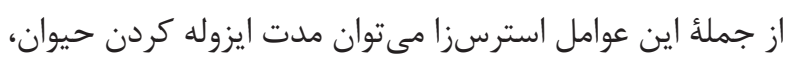

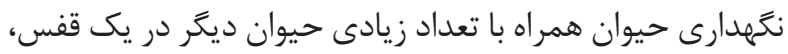

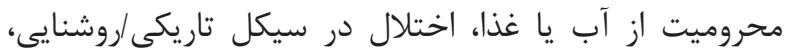

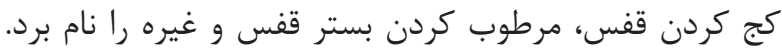

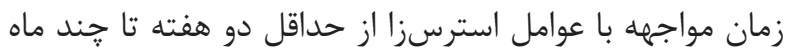

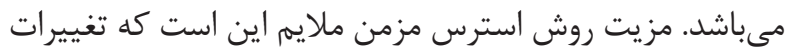

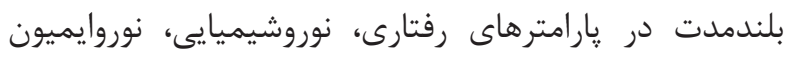

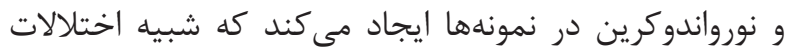

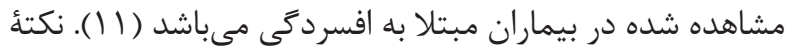

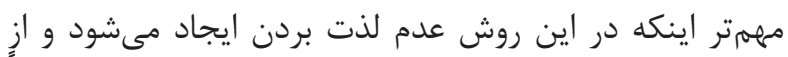

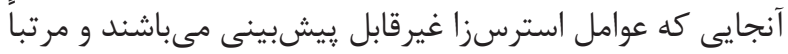

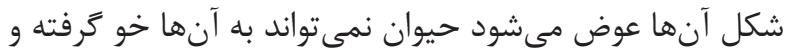

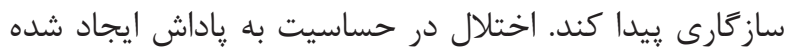

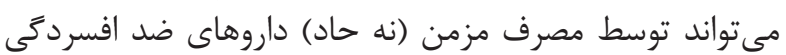

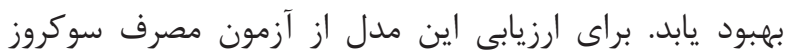
استفاده مىشود كه در ادامه بحث خواهي مدل شاز آزد.

$$
\text { درماندنى آموخته }
$$

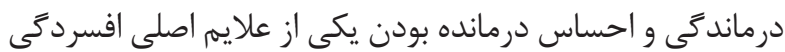

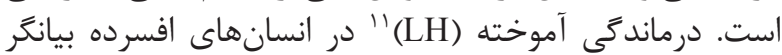

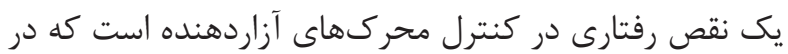

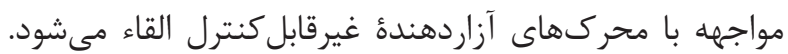

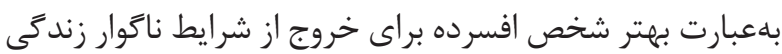

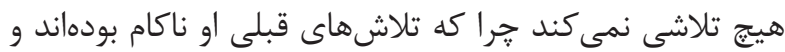

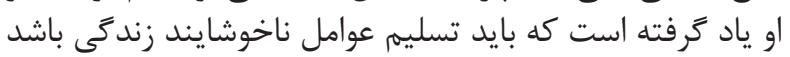

\footnotetext{
${ }^{9}$ Katz and Hersh

${ }^{10}$ Willner

${ }^{11}$ Learned helplessness
} 
ارزيابى ياسخهاى رفتارى مانند فعاليت حركتى، بيش فعالى

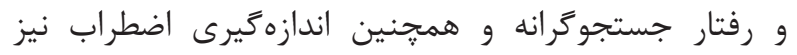

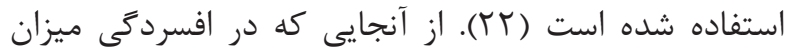

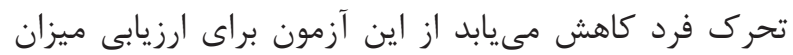
افسردگى استفاده مى شود.

براى انجام اين آزمون از يك جعبهُ رو باز كه كف آن توسط

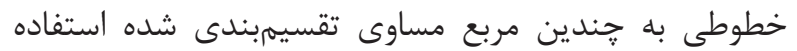

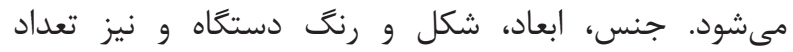

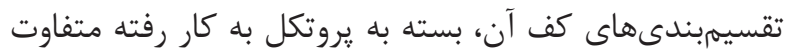

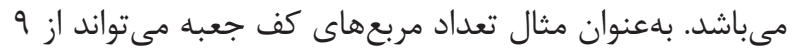

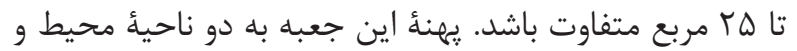

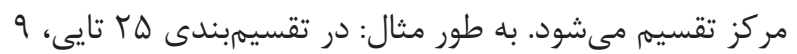

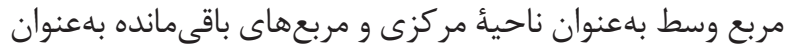

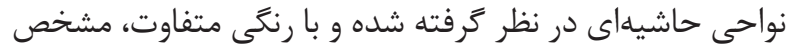

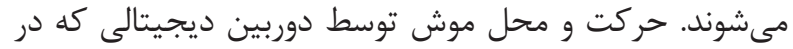

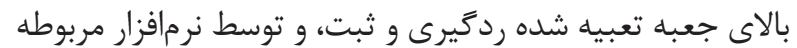

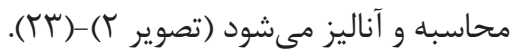
براى انجام آزمون، حيوان را به آرامى و به صورت تصادفى در

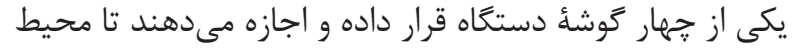

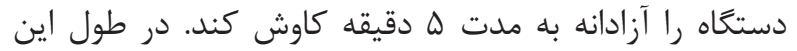

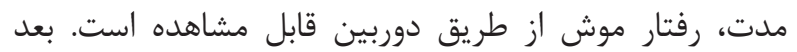

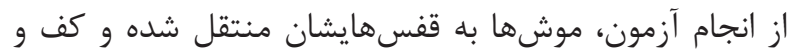

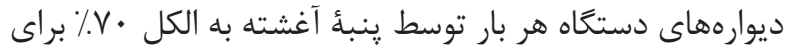

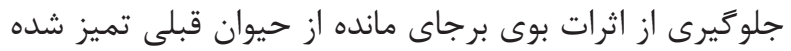

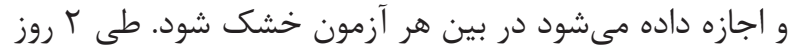

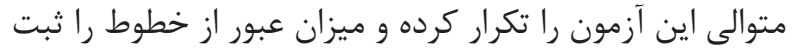

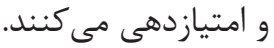

افزايش در زمان كذرانده شده و تعداد ورود به مركز مى تواند

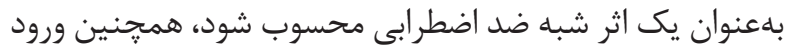

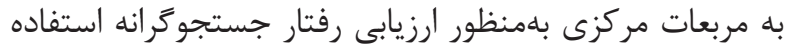

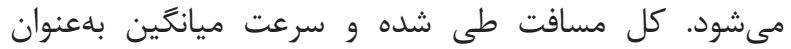

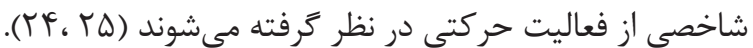

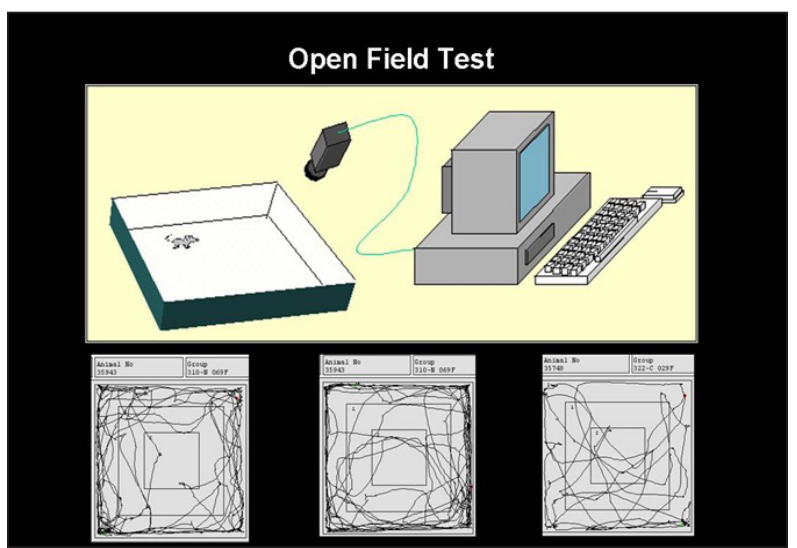

تصوير r- آزمون زمينه باز (rT).

${ }^{12}$ Forced swimming test

${ }^{13}$ Floating

${ }^{14}$ Immobility behavior

${ }^{15}$ Immobility time

$$
\begin{aligned}
& \text { روشهاى ارزيابى افسردىى } \\
& \text { آزمون شناى اجبارى }
\end{aligned}
$$

آزمون شناى اجبارى (FST) "ا يكى از معتبرترين و رايجترين

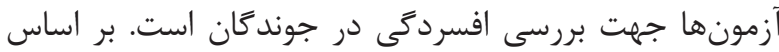

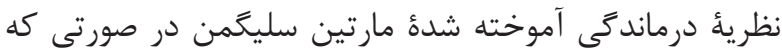

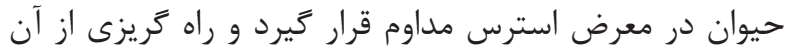

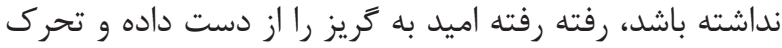

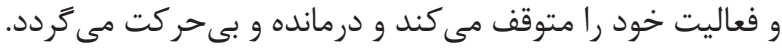

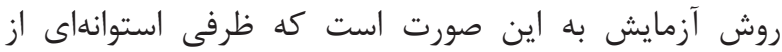

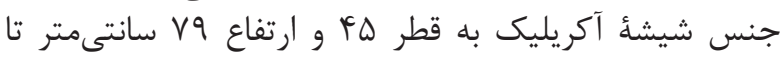

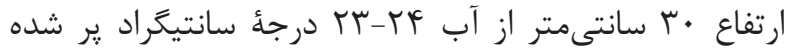

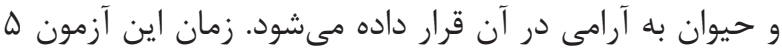

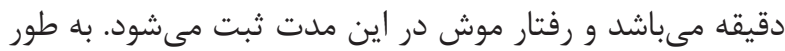

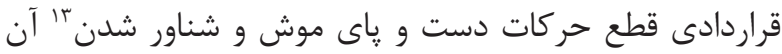

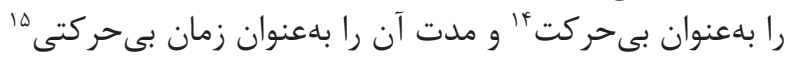

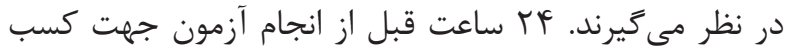

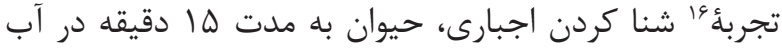

قرار داده مىشود (تصوير (1)-( (1) ).

همانطور كه ذكر شد اين آزمون بازتاب دهندئ يك مرحله از

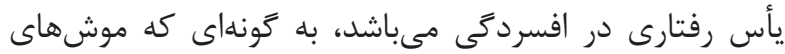

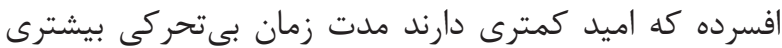

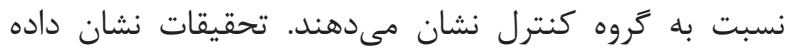

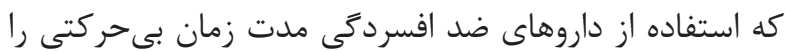

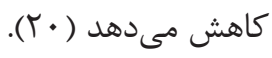

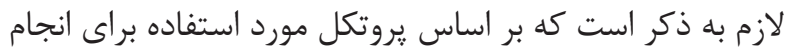

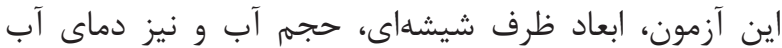

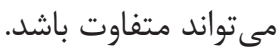

آزمون زمينه باز

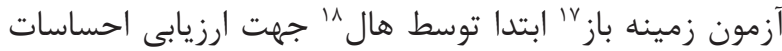

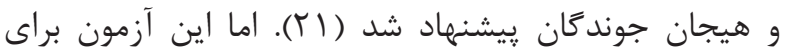

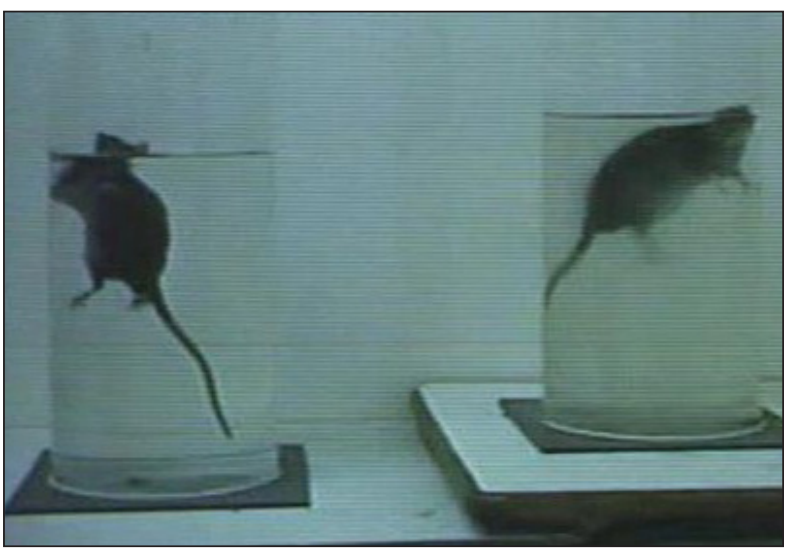

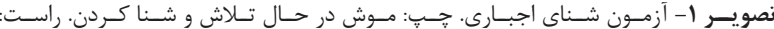

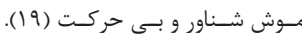
${ }^{16}$ Train
${ }^{17}$ Open field test
${ }^{18}$ Hall
${ }^{19}$ Tail suspension test 
مدت براى ييشَيرى از احتمال خطا در آزمون جاى ظرف آب

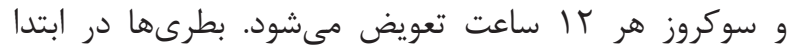

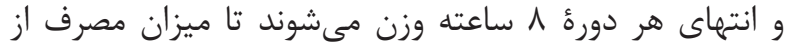

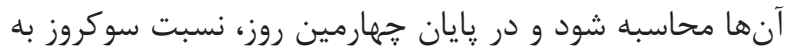

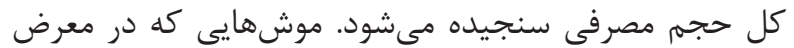

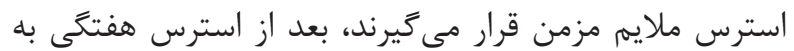

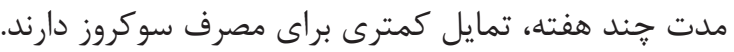

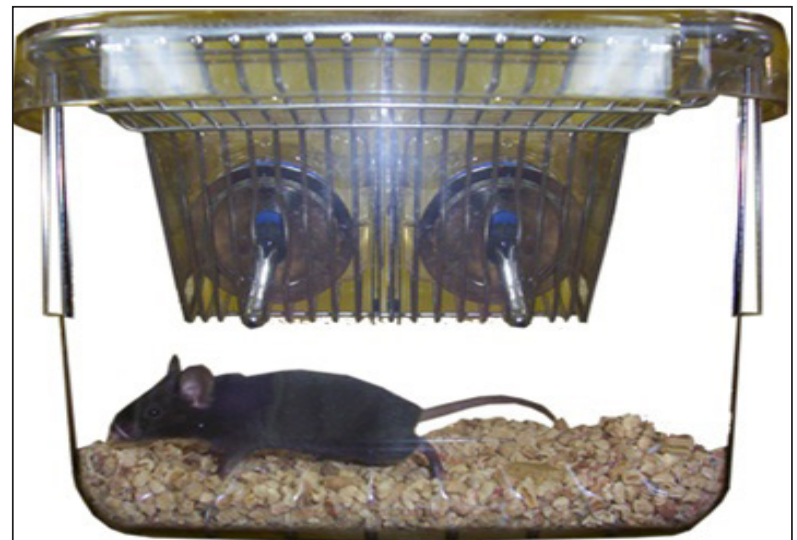

تصوير \$- آزمون ترجيح سوكروز (^)).

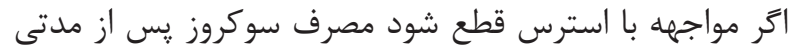

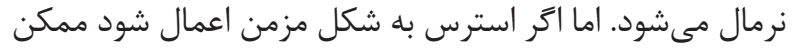

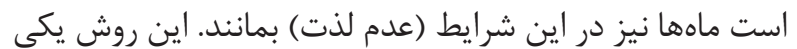

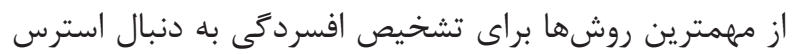

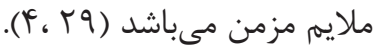

لازم به ذكر است درصد سوكروز در محلول و مدت مد زمان مان انجام

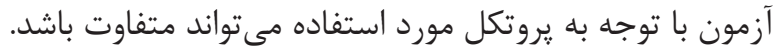

\section{خود تحريكى داخل مغزى}

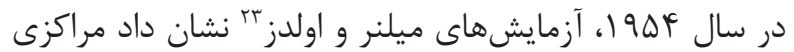

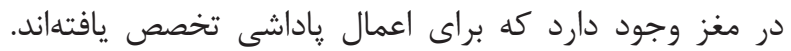

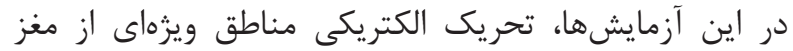

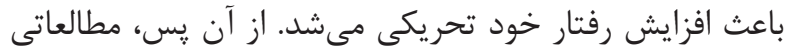

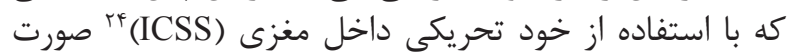

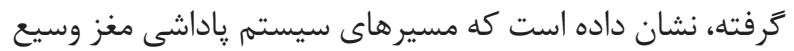

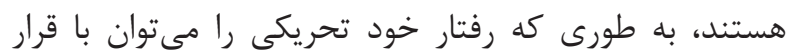

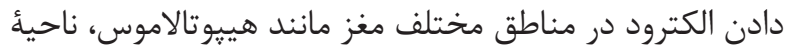

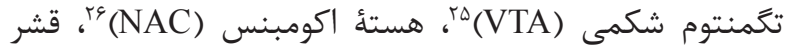

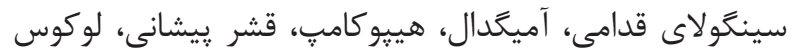

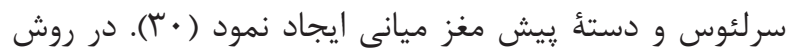

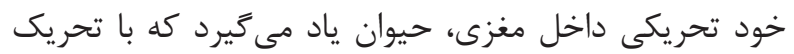

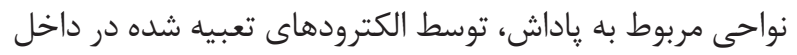
مغزش، مسيرهاى مربوطه را فعال كند. تحت عمل استرئوتاكسى الكترودهاى دوقطبى از جنس فولاد

\footnotetext{
${ }^{20}$ Steru

${ }^{21}$ Sucrose preference test

${ }^{22}$ Habituation

${ }^{23}$ Milner and Olds
}

$$
\text { آزمون آويزان كردن از دم }
$$

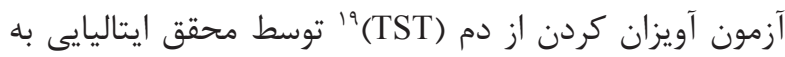

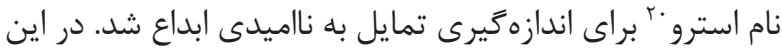

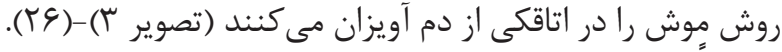

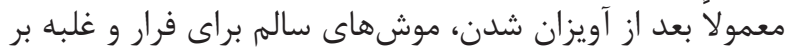

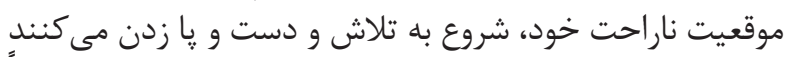

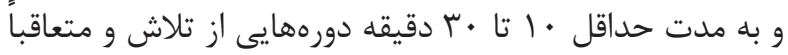
عدم تحرك خواهند داشت.

هر خه موش افسردهتر باشد تلاش كمترى براى فرار از حالت

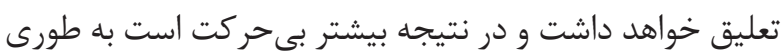

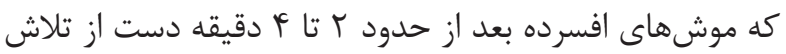

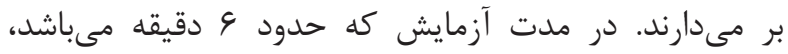

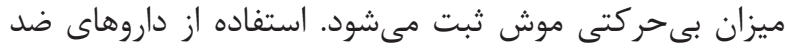

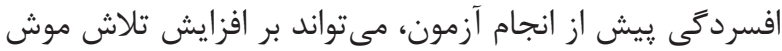

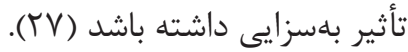

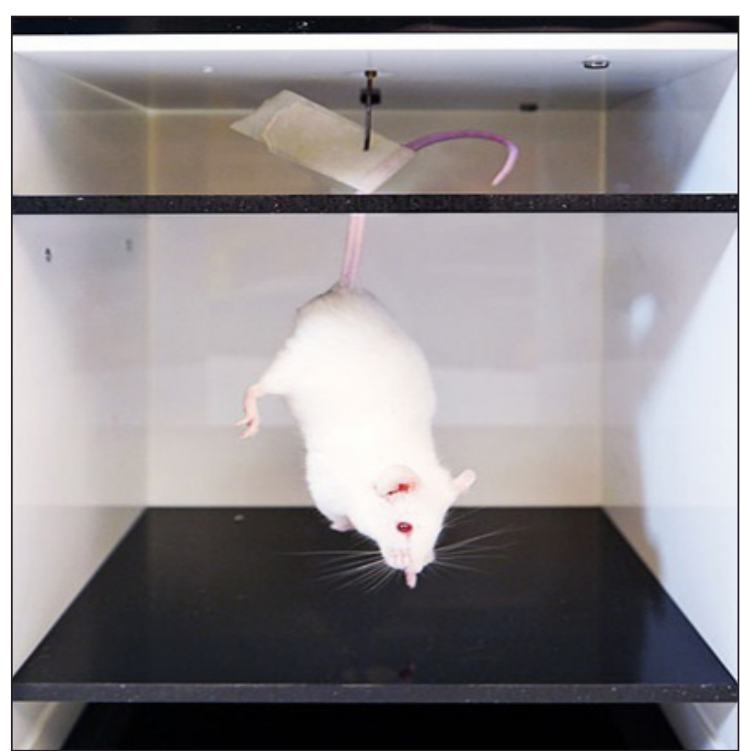

تصوير ץ- آزمون آويزان كردن از دم (צ).

آزمون ترجيح سوكروز

رفتار عدم لذت بردن كه در افراد افسرده ايجاد مىشود باد با آزمون

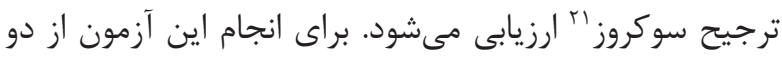

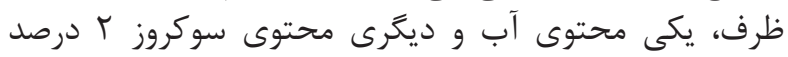

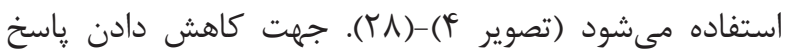

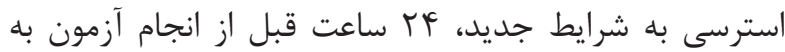

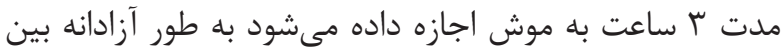

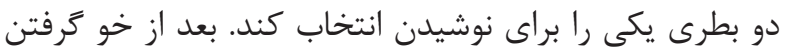

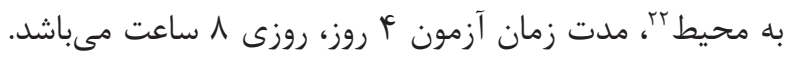

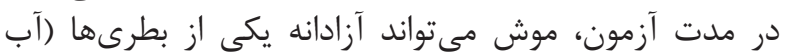

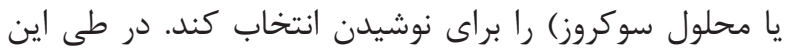

\footnotetext{
${ }^{24}$ Intracranial self-stimulation

${ }^{25}$ Ventral tegmental area

${ }^{26}$ Nucleus accumbens

${ }^{27}$ Stereotaxy
} 
آزمون ماز مر تفع بهعلاوه شكل

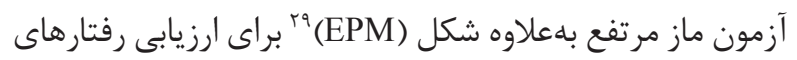

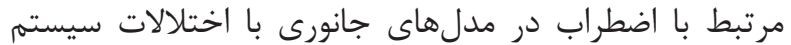

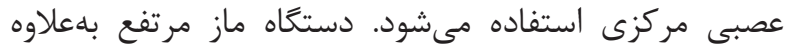

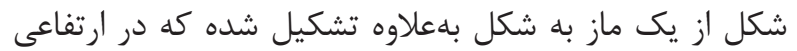

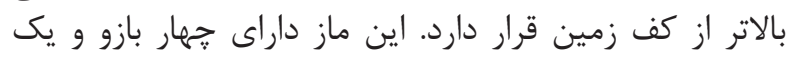

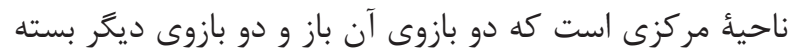

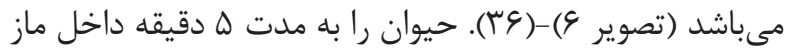

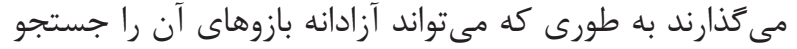

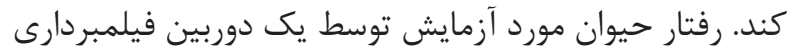

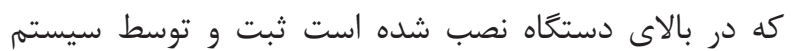

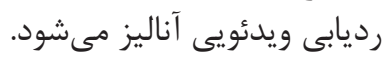

در يايان آزمون، درصد ميزان زمانى كه حيوان در بازوهائ باز

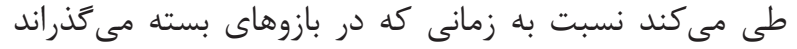

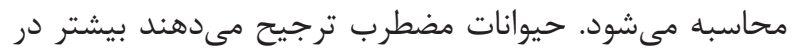

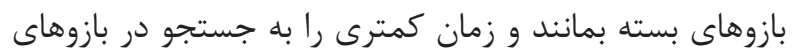

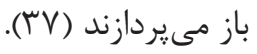

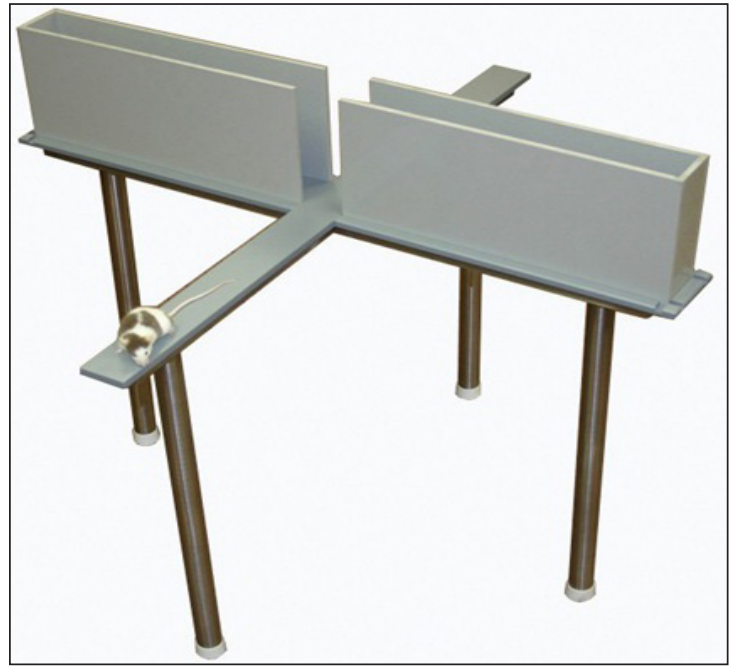

تصوير צ- دستگاه پِاس ماز مرتفع (عץ).

\section{آزمون جعبهُ روشن و تاريك}

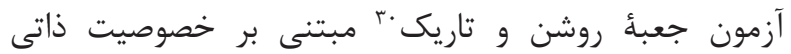

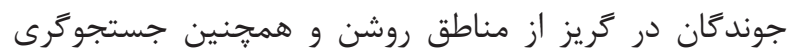

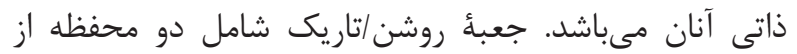

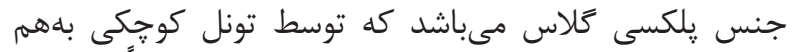

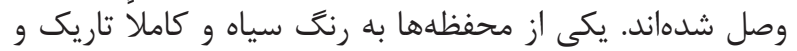

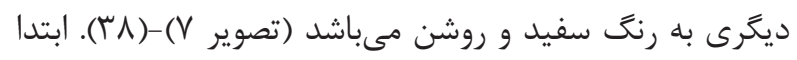

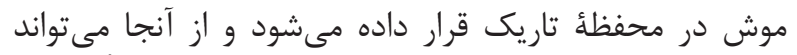

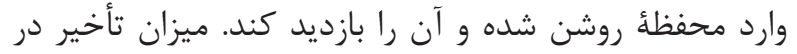

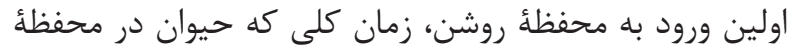

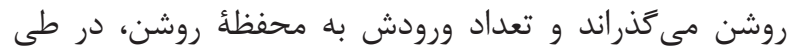

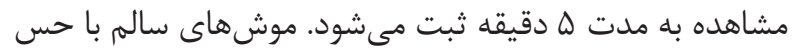

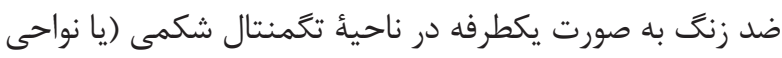

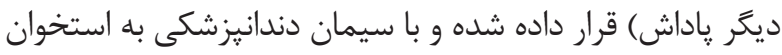

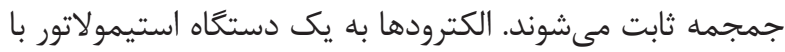

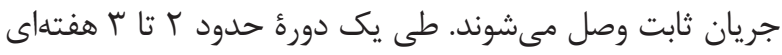

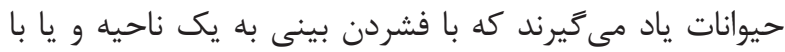

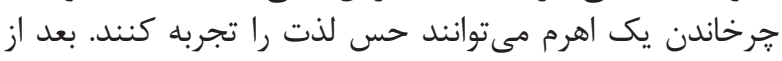

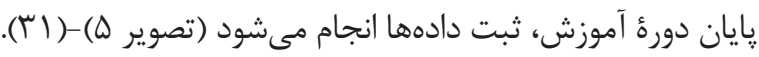

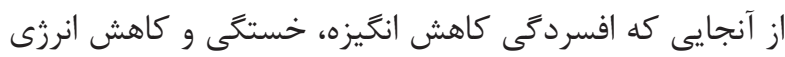

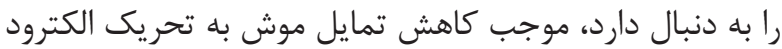

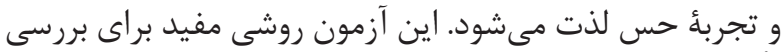

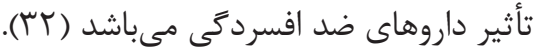

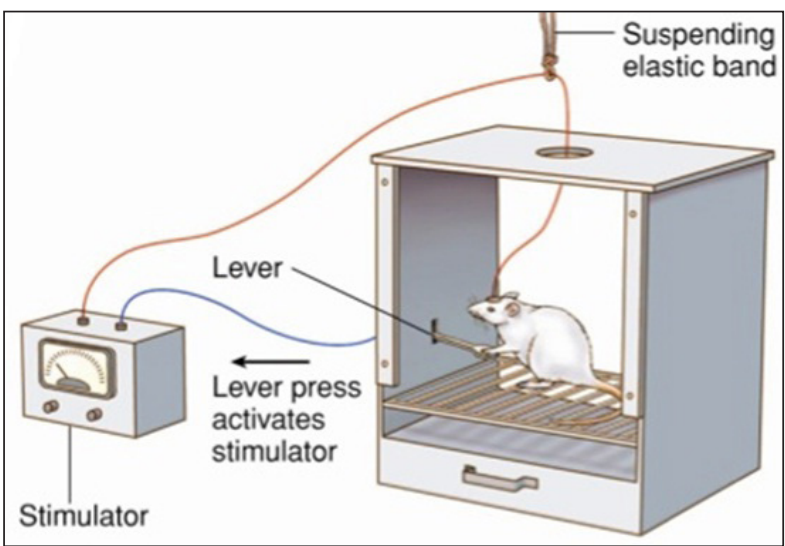

تصوير ه- خود تحريكى داخل مغزى (آ⿱).

\section{آزمون هاييوفازى ناشى از تازگى}

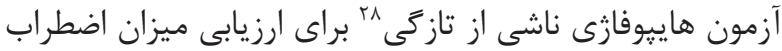

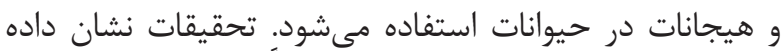

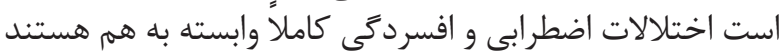

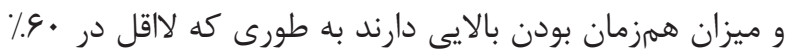

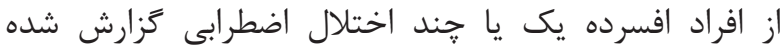

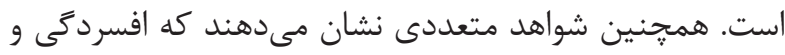

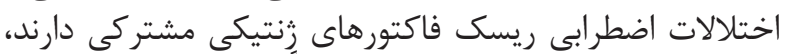

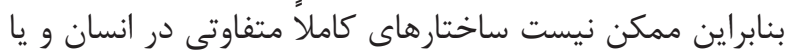

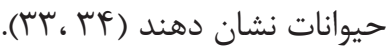

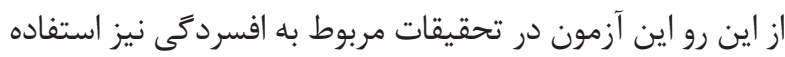

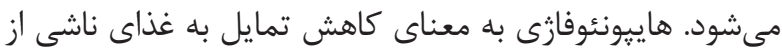

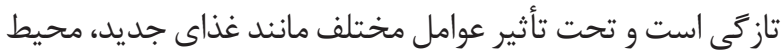

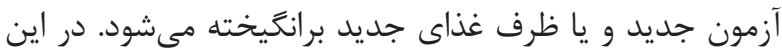

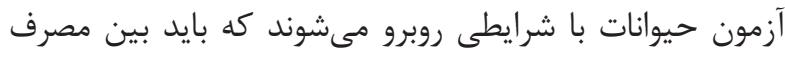

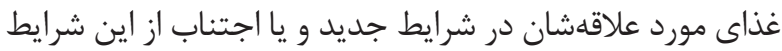

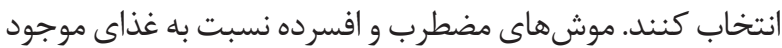

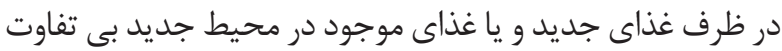

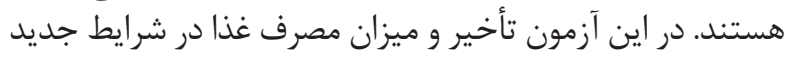

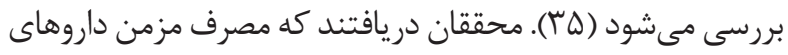

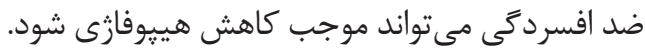

${ }^{28}$ Novelty-induced hypophagia test

${ }^{29}$ Elevated plus maze test

${ }^{30}$ Dark/light box 


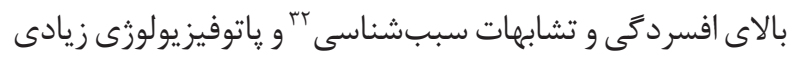

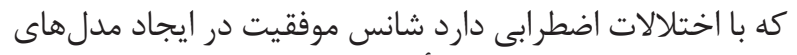

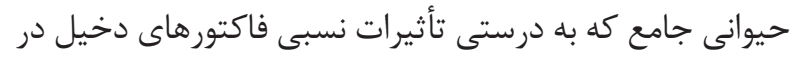

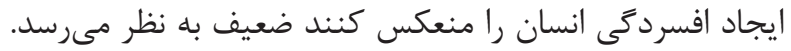

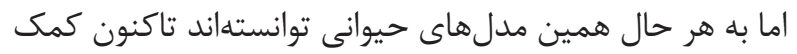

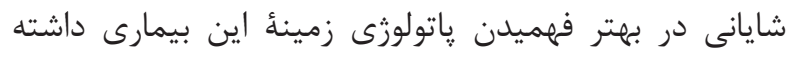

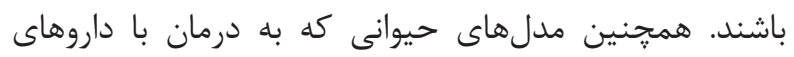

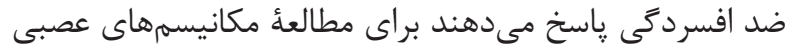

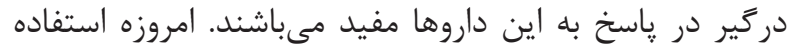

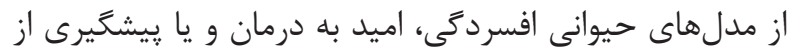

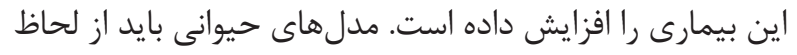

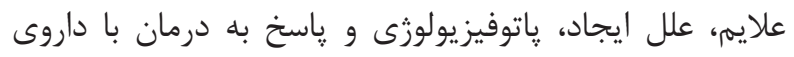

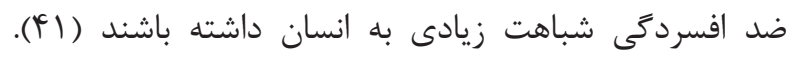

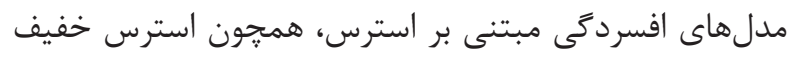

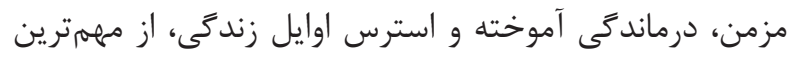

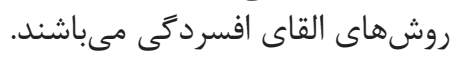

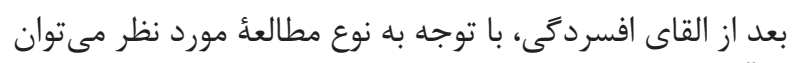

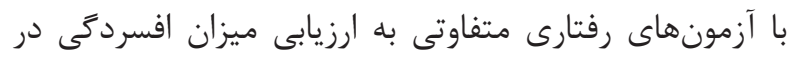

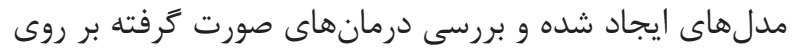
آنها يرداخت. اين روشهاى شها عبارتند ازي:

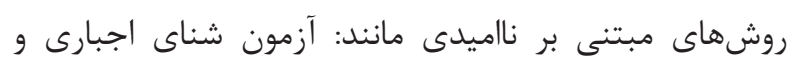
آزمون آويزان كردن از دم نمان

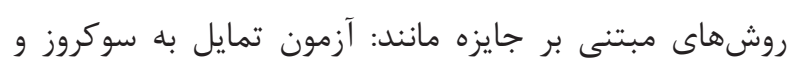

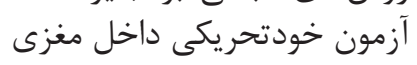

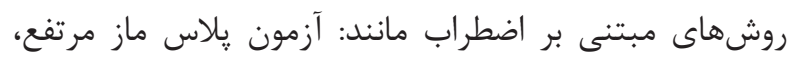

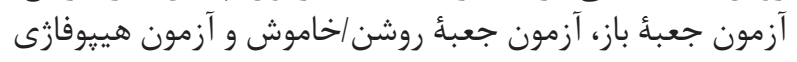
ناشى از تازگى آنى

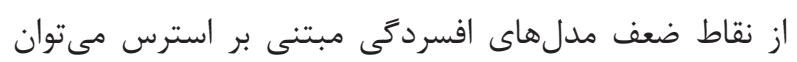

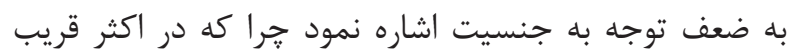

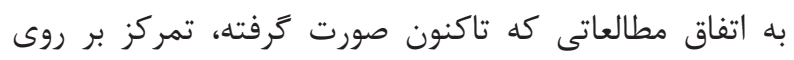

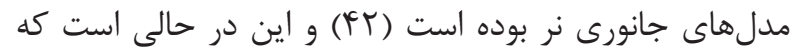

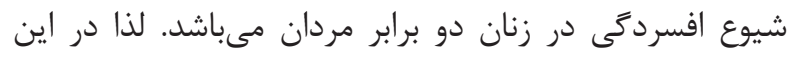

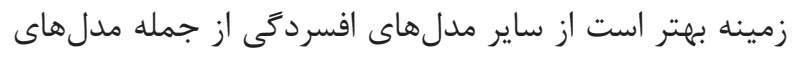

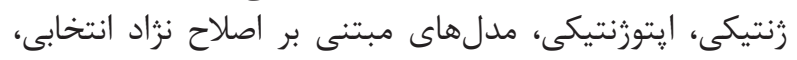

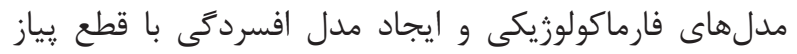

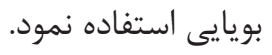

كنجكاوى ذاتى تمايل بالايى به تجربأ مكانهاى جديد دارند،

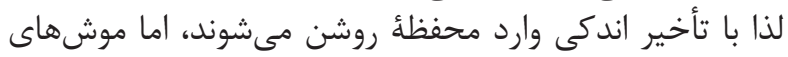

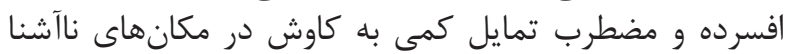

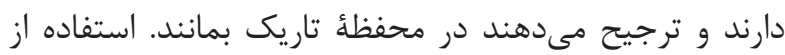

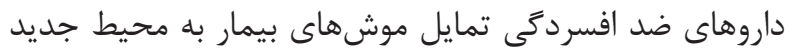

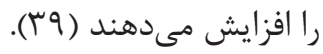

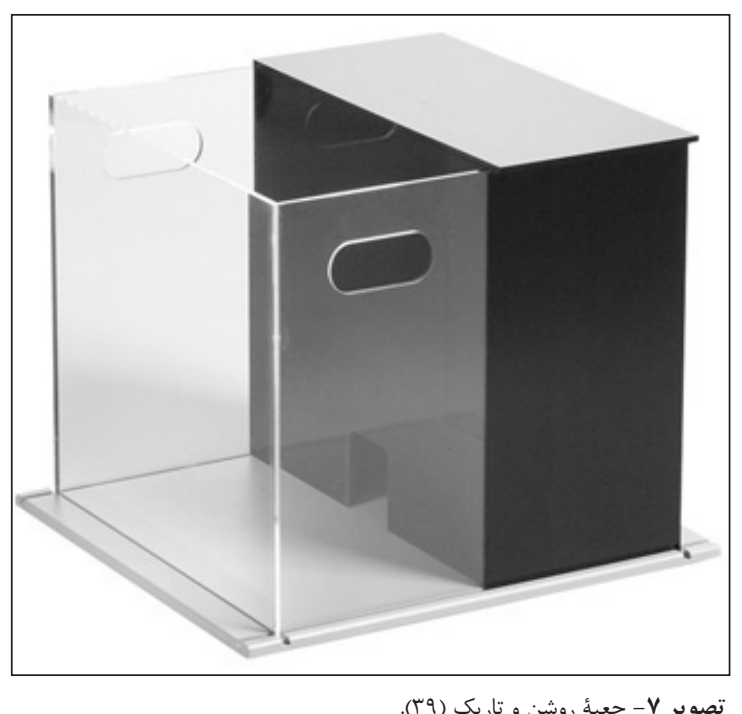

نتيجه

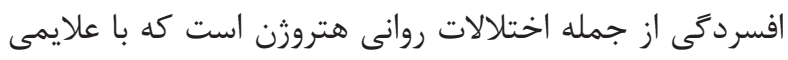

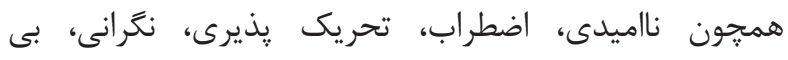

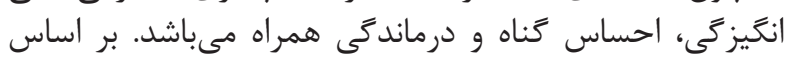

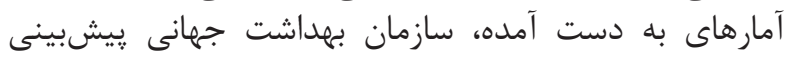

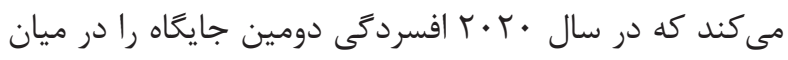

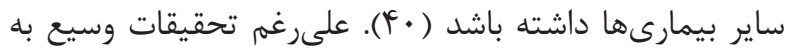

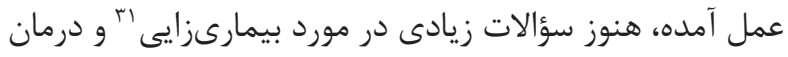

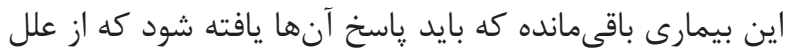

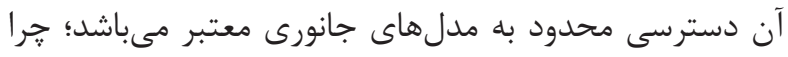

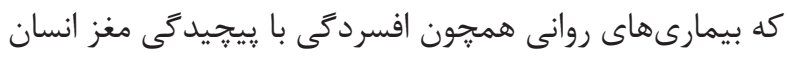

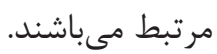

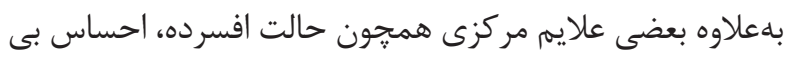

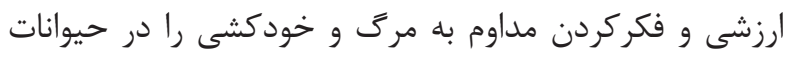

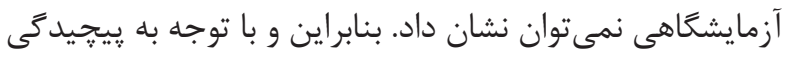

\footnotetext{
${ }^{31}$ Pathogenicity

${ }^{32}$ Etiology
} 
1. Kessler RC, Bromet EJ. The epidemiology of depression across cultures. Annu Rev Public Health. 2013; 34: 119-38.

2. Beck AT, Alford BA. Depression: causes and treatment. $2^{\text {nd }}$ ed. University of Pennsylvania Press. 2009 .

3. Hammen C. Stress and depression. Annu Rev Clin Psychol. 2005; 1: 293-319.

4. Czeh B, Fuchs E, Wiborg O, Simon M. Animal models of major depression and their clinical implications. Prog Neuropsychopharmacol Biol Psychiatry. 2016; 64: 293-310.

5. Bjorkqvist K. Social defeat as a stressor in humans. Physiol Behav. 2001; 73(3): 435-42.

6. Hollis F, Kabbaj M. Social defeat as an animal model for depression. ILAR J. 2014; 55(2): 221-32.

7. Berton O, McClung CA, DiLeone RJ, Krishnan V, Renthal W, Russo SJ, et al. Essential role of BDNF in the mesolimbic dopamine pathway in social defeat stress. Science. 2006; 311(5762): 864-8.

8. Palanza P. Animal models of anxiety and depression: how are females different? Neurosci Biobehav Rev. 2001; 25(3): 219-33.

9. Holly EN, Shimamoto A, Debold JF, Miczek KA. Sex differences in behavioral and neural cross-sensitization and escalated cocaine taking as a result of episodic social defeat stress in rats. Psychopharmacology (Berl). 2012; 224(1): 179-88.

10. Bartlang MS, Neumann ID, Slattery DA, UscholdSchmidt N, Kraus D, Helfrich-Förster C, et al. Time matters: pathological effects of repeated psychosocial stress during the active, but not inactive, phase of male mice. J Endocrinol. 2012; 215(3): 425-37.

11. Willner P. Chronic mild stress (CMS) revisited: consistency and behavioural-neurobiological concordance in the effects of CMS. Neuropsychobiology. 2005; 52(2): 90-110.

12. Katz RJ, Hersh S. Amitriptyline and scopolamine in an animal model of depression. Neurosci Biobehav Rev. 1981; 5(2): 265-71.

13. Pryce CR, Azzinnari D, Spinelli S, Seifritz E, Tegethoff M, Meinlschmidt G. Helplessness: a systematic translational review of theory and evidence for its relevance to understanding and treating depression. Pharmacol Ther. 2011; 132(3): 242-67.

14. Seligman ME, Maier SF, Geer JH. Alleviation of learned helplessness in the dog. J Abnorm Psychol. 1968; 73(3): 256-62.

15. Drugan RC, Basile AS, Ha J-H, Healy D, Ferland RJ. Analysis of the importance of controllable versus uncontrollable stress on subsequent behavioral and physiological functioning. Brain Res Protoc. 1997; 2(1): 69-74.

16. Schmidt MV, Wang X-D, Meijer OC. Early life stress paradigms in rodents: potential animal models of depression? Psychopharmacology (Berl). 2011; 214(1): 131-40.

17. Rice CJ, Sandman CA, Lenjavi MR, Baram TZ. A novel mouse model for acute and long-lasting consequences of early life stress. Endocrinology. 2008; 149(10): 4892-900.

18. Naninck EF, Hoeijmakers L, Kakava-Georgiadou N, Meesters A, Lazic SE, Lucassen PJ, et al. Chronic early life stress alters developmental and adult neurogenesis and impairs cognitive function in mice. Hippocampus. 2015; 25(3): 309-28.

19. Animal research. http://www.fermons-le-ceds.org/ en/animal-research/.

20. Petit-Demouliere B, Chenu F, Bourin M. Forced swimming test in mice: a review of antidepressant activity. Psychopharmacology (Berl). 2005; 177(3): 245-55.

21. Hall C, Ballachey EL. A study of the rat's behavior in a field. A contribution to method in comparative psychology. Univ Calif Publ Psychol. 1932; 6: 1-12.

22. Walsh RN, Cummins RA. The open-field test: a critical review. Psychol Bull. 1976; 83(3): 482-504.

23. CJ H. Animal models of depression. http://psylab. idv.tw/animal\%20models/open\%20field\%20test.jpg.

24. Habr SF, Bernardi MM, Conceicao IM, Freitas TA, Felicio LF. Open field behavior and intra-nucleus accumbens dopamine release in vivo in virgin and lactating rats. Psychol Neurosci. 2011; 4(1): 115-21.

25. Brown RE, Corey SC, Moore AK. Differences in 


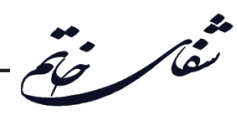

measures of exploration and fear in MHC-congenic C57BL/6J and B6-H-2K mice. Behav Genet. 1999; 29(4): 263-71.

26.Tail suspension test. http://www.bioseb.com/bioseb/ anglais/default/item_id=2_cat_id $=1$ _TailoSuspension 0Test_source $=$ news.php.

27. Cryan JF, Mombereau C, Vassout A. The tail suspension test as a model for assessing antidepressant activity: review of pharmacological and genetic studies in mice. Neurosci Biobehav Rev. 2005; 29(45): 571-625.

28. Hamidi A. Comparison of animal models in enriched environments. https://mazeengineers.com/comparisonanimal-models-enriched-environments/

29. Cline BH, Anthony DC, Lysko A, Dolgov O, Anokhin K, Schroeter C, et al. Lasting downregulation of the lipid peroxidation enzymes in the prefrontal cortex of mice susceptible to stress-induced anhedonia. Behav Brain Res. 2015; 276: 118-29.

30. Wise RA. Addictive drugs and brain stimulation reward. Annu Rev Neurosci. 1996; 19(1): 319-40.

31. Claffey P. Biological Foundations. http://mikeclaffey. com/psyc2/notes-cog-motivation-emotion.html.

32. Carlezon WA, Chartoff EH. Intracranial selfstimulation (ICSS) in rodents to study the neurobiology of motivation. Nat Protoc. 2007; 2(11): 2987-95.

33. Ohara K, Suzuki Y, Ochiai M, Tsukamoto T, Tani K, Ohara K. A variable-number-tandem-repeat of the serotonin transporter gene and anxiety disorders. Prog Neuropsychopharmacol Biol Psychiatry. 1999;
23(1): 55-65.

34. Helmuth L. In sickness or in health? Science. 2003; 302(5646): 808-10.

35. Dulawa SC, Hen R. Recent advances in animal models of chronic antidepressant effects: the noveltyinduced hypophagia test. Neurosci Biobehav Rev. 2005; 29(4): 771-83.

36. Elevated plus maze. http://www.stoeltingco.com/ anymaze/video-tracking/bundles/elevated-plus-mazeany-maze-bundle.html.

37. Walf AA, Frye CA. The use of the elevated plus maze as an assay of anxiety-related behavior in rodents. Nat Protoc. 2007; 2(2): 322-8.

38. Stoelting Co. light/dark box. http://www.stoeltingco. com/anymaze/mazes/anxiety-depression/light-darkbox.html.

39. Chourbaji S, Urani A, Inta I, Sanchis-Segura C, Brandwein C, Zink M, et al. IL-6 knockout mice exhibit resistance to stress-induced development of depressionlike behaviors. Neurobiol Dis. 2006; 23(3): 587-94.

40. Murray CJ, Lopez AD. Alternative projections of mortality and disability by cause 1990-2020: Global Burden of Disease Study. Lancet. 1997; 349(9064): 1498-504.

41. Willner P, Mitchell P. The validity of animal models of predisposition to depression. Behav Pharmacol. 2002; 13(3): 169-88.

42. Hua-cheng Y, Cao X, Das M. Behavioral animal models of de-pression. Neurosci Bull. 2010;26(4): 327-37. 